Linköping Studies in Arts and Sciences No. 770

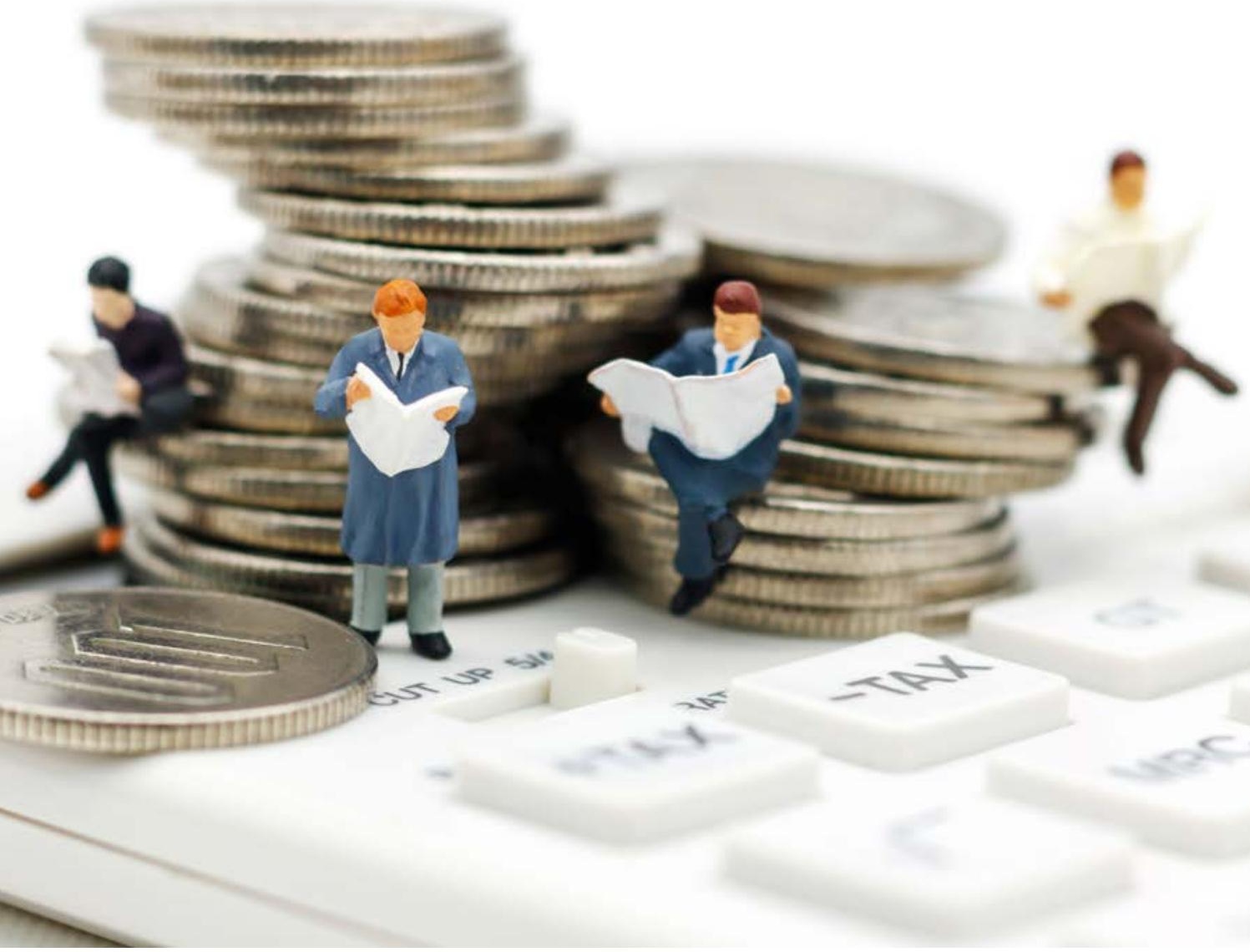

Financial Literacy, Motivated

Reasoning, and Gender

Essays in Behavioral Economics

\title{
Thérèse Lind
}




\title{
Financial Literacy, Motivated Reasoning, and Gender
}

Essays in Behavioral Economics

\author{
Thérèse Lind
}

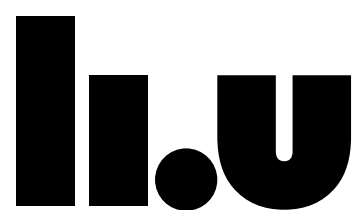

LINKÖPING UNIVERSITY

Department of Management and Engineering

Linköping University, Sweden

Linköping 2019 
Financial Literacy, Motivated Reasoning, and Gender

Essays in Behavioral Economics

CThérèse Lind, 2019

Cover/picture/Illustration/Design: Rattana.R/Shutterstock.com

Published article has been reprinted with the permission of the copyright holder.

Printed in Sweden by LiU-Tryck, Linköping, Sweden, 2019

ISBN: 978-91-7685-060-2

ISSN: 0282-9800 


\section{Acknowledgements}

In writing this, my time as a PhD student has almost come to a close. I would never have been able to finish this project without the support of my wonderful family, my awesome friends and my precious colleagues who always supported my desire to pursue my interests. Even so, there are several people to whom I am especially grateful.

I thank Ali Ahmed, my main supervisor for our discussions and for the constant encouragement and support. He was a help in good times and in rough ones and always lent a sympathetic ear. I'm grateful for his ability to improve my work and to see the best in my research ideas. I always felt welcome in his office, and I will greatly miss stopping by for an inspiring chat and of course a candy bar.

Gustav Tinghög, my co-supervisor, also deserves thanks. His attention to detail and his way of writing is inspiring. His excitement to do world-conquering research is contagious and after meetings with him I was eager to get started on my own research. I have always been impressed by his creativity, his tenaciousness, and not least, his ability to make people laugh. His dedication to JEDI Lab and to our collaborative research is very encouraging.

Daniel Västfjäll, my other co-supervisor, was always willing to listen to me and offered helpful suggestions to improve my work. His ability to come up with exciting research projects and his way of always knowing everything about the latest and most interesting papers impressed me. His dedication to JEDI Lab is a source of inspiration to padawans and fully fledged jedi alike.

Göran Hägg, Head of the Economics Division, had confidence in me from the beginning. Without him, I never would have started this journey. He always made me feel like I was an important part of our workplace. His dedication to our students and to teaching set a high standard for the whole department.

Linnea Tengvall, Director of Studies at the Economics Division encouraged me to come work at the university. Her dedication to teaching and tireless effort to keep improving herself is inspiring. I hope that she pursues the role of headmaster someday.

Camilla Strömbäck, my office roommate and $\mathrm{PhD}$ colleague was with me from the start of this journey. She made doctoral study fun and I enjoyed working with her so much. I hope that she feels the same about me.

I would like to acknowledge Länsförsäkringar Alliance for funding the research presented in this thesis. 
I am also grateful to my colleagues at the Economics Division for making our workplace an exciting place to work. I also want to thank my colleagues from JEDI Lab for the great seminars, generous feedback, and fun after-work activities.

Before starting my journey as a $\mathrm{PhD}$ student, I was an undergraduate at Linköping University. Therefore, many of my current and former colleagues were also my teachers and they were the people who stimulated my interest in economics. I am especially grateful to Inger Asp for encouraging my interest in econometrics. Her genuine dedication to teaching and econometrics made me want to know more, for that I will forever be appreciative.

Lastly, I would like to acknowledge one colleague who was here when I started this journey, but whom is not with us today. Jan Lindvall is missed by the entire department. He was the first faculty member to let me teach a part of his course. I still remember the excitement I felt after teaching my first seminar. I met him in the corridor right after it ended, still feeling the teaching rush, and I could tell that he knew the feeling well. His dedication to teaching was so inspiring.

Linköping

April 6, 2019

Thérèse 


\section{Abstract}

I wrote this thesis to create a better understanding of how individual characteristics influence our feelings, our behavior and our way of interpreting information. My focus is on financial behavior and financial information, however I also consider a political context. I investigate the (usually) enabling abilities of financial literacy and numeracy. I also consider impediments such as stereotype threat and motivated reasoning, which can prevent people from engaging in certain behaviors or from interpreting information objectively. Both processes stem from valued beliefs and psychological foundations, consequently peoples' efforts, decisions, and evaluations are based on them.

The first essay, "Competence, confidence, and gender: The role of perceived and actual financial literacy in household finance," broadens our understanding of the benefits of financial competence. I contrast perceived and actual levels of financial literacy, and consider the role of numeracy and cognitive reflective ability. I conclude that perceived and actual levels of financial literacy positively affect behavior and wellbeing; however, perceived financial literacy more so than actual financial literacy. No such effect is observed for numeric ability and cognitive reflection. Furthermore, women are more anxious about financial matters even though they tend to engage more frequently in the considered financial behaviors.

The second essay, "Threatening finance? Examining the gender gap in financial literacy," continues my exploration of the relationship between gender and financial literacy. In a series of studies, I investigate whether the observed gender gap in financial literacy can be identified in nonnumerical contexts, if it can be associated with confidence in financial matters, and if it can be attributed to stereotype threat, which posits that inbuilt prejudices about gender and finance undermine women's performance of tasks that involve finance. The results show that the observed gender gap in financial literacy is robust even in nonnumerical financial contexts and suggest that a stereotype threat for women in the financial domain might be present. The gender gap in financial literacy could not be attributed to a difference in (displayed) confidence.

In the third essay, "Preferences for lump-sum over divided payment structures," I investigate whether or not people display systematic preferences for lump-sum or divided payment structures and how these preferences differ in gain (benefit) and loss (payment) situations. I investigate what happens when payments belong to a single underlying event, such as when people can choose to pay immediately or in installments. I also examine whether or not individual differences in time preferences, risk preferences, numeracy, and financial literacy 
are associated with preferences for one payment structure or the other. The aggregate results show a tendency for people to prefer obtaining and paying money in lump sums. I find no systematic indication that the considered individual differences play a role in this type of decision.

The fourth essay, "Motivated reasoning when assessing the effect of refugee intake," inquires into differences in worldview ideology, whether people identify as nationally or globally oriented, hinder them from objectively interpreting information. I use an experiment to find out if people display motivated reasoning when interpreting numerical information about the effects of refugees on the crime rate. Our results show evidence of motivated reasoning along the lines of worldview ideology. However, individuals with higher numeric ability were less likely to engage in motivated reasoning, leading to the conclusion that motivated reasoning is more likely to be driven by feelings and emotional cues than by deliberate analytical processes. 


\section{Table of Contents}

Introduction $\quad 1$

Key terms and concepts $\quad 2$

Method and data 5

$\begin{array}{lr}\text { Some reflections on the findings } & 8\end{array}$

Summary of the Thesis 9

$\begin{array}{ll}\text { References } & 13\end{array}$

\section{Essay I}

Competence, confidence, and gender: The role of perceived and actual financial

literacy in household finance. Thérèse Lind, Kenny Skagerlund, Camilla Strömbäck, Daniel Västfjäll and Gustav Tinghög.

\section{Essay II}

Threatening finance? Examining the gender gap in financial literacy. Thérèse Lind.

\section{Essay III}

Preferences for lump-sum over divided payment structures. Thérèse Lind.

\section{Essay IV}

Motivated reasoning when assessing the effect of refugee intake. Thérèse Lind, Arvid Erlandsson, Daniel Västfjäll and Gustav Tinghög. Forthcoming in Behavioural Public Policy. 



\section{Introduction}

We interpret information and make decisions every day. Many of these decisions are financial. We weigh the pros and cons of buying something now or later, we make loan payments, we compare products and services, and if there is money left in the account at the end of the month we might consider investing it in some sort of financial instrument. Some of these decisions involve making tradeoffs in time, and balancing risks and returns. It also requires an ability to consider several possible future outcomes. These are difficult decisions, even for professionals. In addition, we live in a fast-paced world. News and information are live streamed to us and we are expected to make sense of it on our own, without someone having processed it beforehand. We are expected to be our own business managers in charge of complex financial decisions, making difficult tradeoffs in time and money, evaluating politically sensitive or difficult information, and interpreting numbers and statistics. This is a cognitively demanding environment, and requires skills to handle the job.

In an ideal world we handle information objectively and use our abilities to their maximum capacity. In reality, however, several things pile up to cloud our objectivity and limit our abilities. We procrastinate (O'Donoghue \& Rabin, 2001), we do not feel equipped to handle our finances (Kaya, 2014), we worry about them (Fünfgeld \& Wang, 2009), we let our preexisting beliefs and stereotypes guide our decisions and we evaluate information in a biased way (Drummond \& Fischhoff, 2017; Washburn \& Skitka, 2017).

Previous research has shown a large heterogeneity in people's ability to interpret information and make everyday decisions. For example, in an earlier study, my colleagues and I examined the role of self-control in financial behavior and financial wellbeing (Strömbäck et al., 2017). We found that people with more self-control were more likely to engage frequently in sound financial practices, such as saving money from every paycheck and comparing products before making a purchase. The results also showed that people with more self-control were less anxious about financial matters and felt more secure in their present and future financial situation. In this thesis I investigate how other abilities, most notably, financial literacy and numeracy can guide our decisions and interpretations. I also consider disabling processes such as stereotype threat and motivated reasoning. These processes can hinder people from engaging in certain behaviors or from interpreting information objectively. However, these processes stem from valued beliefs and psychological foundations. 
In the next section I will elaborate on key concepts mentioned in this introduction to give the reader a better understanding of frequently used terms throughout the thesis. I will then discuss the type of data used in the individual studies and discuss their advantages and disadvantages.

\section{Key terms and concepts}

Financial literacy is considered important for financial decision making (Alessie et al., 2011; Almenberg \& Widmark, 2011; Lusardi, 2008). Financial literacy is often described as the ability to use skills and knowledge to navigate a complex financial landscape (Hung et al., 2009). Financial literacy can be seen as an investment in human capital (Becker, 1962; Lusardi \& Mitchell, 2014). By becoming financially literate, people will be able to use sophisticated financial instruments and therefore become more likely to prosper financially. Financial literacy is usually measured by a series of multiple-choice questions (Huston, 2010). Questions about "the Big Three"- compound interest rate, inflation and diversification (see e.g.,Lusardi \& Mitchell, 2008) — are the most widely used. In this thesis I use the terms "financial literacy" and "financial knowledge" synonymously. However, there is a conceptual difference between as financial literacy (which is an ability) and financial knowledge (which is usually measured).

Numeric ability is also considered essential in decision-making. This concept appears in all of the essays comprising this thesis. "Numeric ability" or "numeracy," terms that I also use interchangeably, can be defined as the ability to interpret numbers and to process basic numerical concepts, quantitative estimations, probabilities, and ratios (Cokely et al., 2012; Peters et al., 2006). It has been shown to be important for several types of decision-making in relation to health care, finance and metacognitive tasks to mention a few (Banks \& Oldfield, 2007; Ghazal et al., 2014; Reyna et al., 2009). My colleagues and I found that numeracy could be an important determinant of financial literacy. However it was not only the numeracy that was important; people's emotional attitudes to numbers, as measures on a mathematical anxiety scale, determined financial literacy (Skagerlund et al., 2018).

A consistent finding concerning financial literacy, however, is that men have a better knowledge of financial concepts than women (Almenberg \& Dreber, 2015; Driva et al., 2016; Fonseca et al., 2012; Lusardi \& Mitchell, 2008). This suggests that the prerequisites for financial wellbeing is dispersed unequally throughout society based on gender. Results for the relation between gender and numeracy are less homogeneous. Some studies find differences favoring men (Hedges \& Nowell, 1995; Rosselli et al., 2009) while others find that these 
differences are decreasing over time (Feingold, 1988). Still other studies find men outperforming women in specialized samples, but women performing better than men in general samples (Hyde et al., 1990).

In the first essay of this thesis my co-authors and I find significant gender differences in both actual and perceived financial literacy, in numeracy and in cognitive reflection in a diverse sample of the Swedish population. Since financial matters are seldom devoid of numbers, even small differences in numeracy could be important to consider in the financial domain. Since gender differences have been observed in important decision-making correlates, it is essential to consider the potential consequences. For example, pension reforms have increased individual responsibility in financial decision making. If financial literacy and numeric ability are needed to handle once personal finances, this type of policy increases the risk of social polarization in terms of disparities in financial opportunities. However, we also need to consider what the observed gender differences are telling us, and it is of great importance to determine the underlying explanations. Otherwise remedial policies risk backfiring.

Something else that affects everyday life is motivated reasoning, which can be characterized as the struggle between a desire for accuracy and a desire for confirming alreadyheld beliefs (Bénabou, 2015; Kunda, 1990; Van Bavel \& Pereira, 2018). With regards to evaluating information, this translates into people assessing information in a biased manner in order to support a belief rather than objectively considering that information (Bastardi et al., 2011; Kahan et al., 2012; Lord et al., 1979; Nickerson \& Louis, 2008). In theoretical models, people are presumably capable of adapting their beliefs when confronted with new information. However, in the presence of motivated beliefs, this update process will be biased, or may not even take place at all. Instead, people process the information to fit their (motivated) beliefs. In addition, these motivated beliefs often fulfill important psychological needs (see e.g., Bénabou and Tirole, 2016; Epley and Gilovich, 2016; Kunda 1990). People hold certain beliefs partly because it makes them feel good, not because they are correct. For this reason, people can be motivated to reach particular conclusions to maintain a certain worldview.

Another example of a motivated goal could be the need for people to fit into certain social groups. Motivated reasoning can steer people away from behaviors or practices that they cannot conform to. This phenomenon has many similarities with stereotype threat. Usually this concept is associated with a self-experienced threat of confirming a negative stereotype. At the same time, it also refers to a broader tendency to disengage from matters connected to a stereotyped domain (Steele et al., 2002; von Hippel et al., 2015). If a group of people tell 
themselves that a certain behavior or ability is not desirable or suitable for them, that it is too difficult, this belief can be reinforced by motivated reasoning. People therefore sometimes become resistant to evidence and engage in non-Bayesian behaviors such as information avoidance, wishful thinking, and reality denial. I would even claim that motivated reasoning can reinforce a stereotype threat.

Bénabou's (2015) framework is helpful for structuring one's thoughts about this (see Figure 1). He combines several models into a single framework, but I find it instructive to consider the model for self-motivation and beliefs distortion. This is very closely linked to the notion of stereotype threat. A risk-neutral individual $(i)$ has a time horizon of three period: 0,1 and 2. At time $t=1$ the individual has to make a decision, interpret information, or perhaps engage in a behavior; this action is denoted by $e^{i}$ (and $e^{i} \in 0,1$ ). This action is associated with a cost $c e^{i}$ where $c>0$. In period 2 the individual will gain the utility of $U_{2}^{i}=V\left(\theta, e^{i}, c, k_{0}^{i} \mid \sigma\right)$. The utility depends on the action taken, $e^{i}$, the state of the world (which can be low or high, $\sigma \in H, L$ ) which determine the return on the undertaking of $\theta$. The utility is also influenced by $k_{0}^{i}$, an initial stock of, for example, wealth, human or social capital, or even genes. In Period 0 when information about the project value $\theta$ may be received the evaluation is done in relation to the individuals' posterior beliefs, these beliefs are carried over to the next period. In addition, the individual's effort decision at time $t=1$ is subject to a temptation problem. The cost is evaluated ex ante (at $t=0$ ), however, at the moment when it must actually be incurred it is perceived as $c / \beta$ where $\beta<0$, represent hyperbolic discounting or weakness of will.

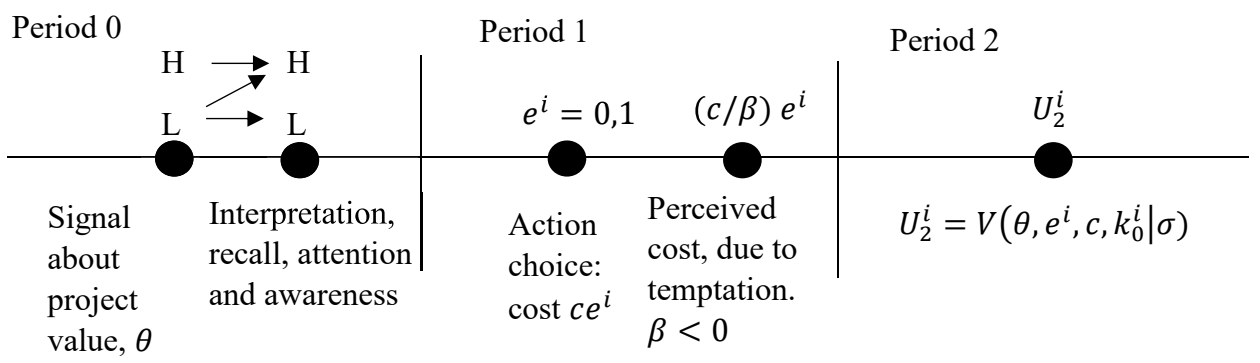

Figure 1. Framework of self-motivation and beliefs distortion (Bénabou, 2015).

Take the example of engaging in a financial behavior, such as setting up a retirement savings account, and consider it in the framework presented in Figure 1. First people interpret signals about the worth of the action; does it seem easy or difficult? Can I handle it on my own, do I 
know where to turn? If people from the start have the beliefs that financial matters are difficult, these beliefs constitute the basis for interpreting the signals about the behavior. This makes the behavior seem more difficult than it is and perhaps people even misinterpret the value of the action (from an objective standpoint; for the individual the chosen behavior maximizes utility). In period 1, when it is time to realize the behavior, the cost associated with the action becomes inflated and people fall prey to lack of will power. Perhaps, saying, "maybe I can set up that account tomorrow, retirement is still a long way from now." In addition, people's initial stock, $k_{0}^{i}$, of for example financial knowledge may also vary with peoples preexisting beliefs.

As this example is intended to show, motivated reasoning is, probably present in all everyday decisions. We usually hope to minimize the cognitive cost of making decisions or interpreting information and one of the easiest strategies of doing so is to choose the option that we feel familiar with beforehand (Bénabou, 2015). In many situations this process is of great help to us, it makes our everyday decisions more manageable and pleasant. Motivated reasoning is commonly investigated within the political realm (Bolsen et al., 2014; Kahan et al., 2012; Dunlap et al., 2016; Washburn \& Skitka, 2017). Here people tend to be outspoken, which makes it easier to measure and quantify the effects of motivated reasoning. As can be seen from the topics of these essays, my research interest focuses on everyday financial decision-making. In this domain it is much less obvious to pinpoint how motivated reasoning can affect our decisions. I speculate that motivated reasoning could affect people's tendency to invest in abilities such as financial literacy. I also investigate such tendencies in Essay II, where I study the differences in financial literacy between men and women. It is clear to me that stereotype threat and motivated reasoning are closely intertwined. However, this is only an attempt to find less outspoken types of polarization that can affect us in ways we do not yet fully understand. My hope is that future research will continue this line of inquiry and investigate how motivated reasoning can affect aspects other than the political sphere in daily life.

\section{Method and data}

Today experiments are a common method to generate data in the social sciences. Experiments give researchers unique control to test hypotheses and theoretical predictions. In many disciplines, experiments, or randomized control trials are considered the gold standard to ensure causality (Falk \& Heckman, 2009). Almost all other research methods attempt to emulate the experimental process and make the results appear "as if" the data was generated by a controlled experiment. Harrison and List (2004, p. 1009) point out that "In some sense every empirical 
researcher is reporting the results of an experiment. Every researcher who behaves as if an exogenous variable varies independently of an error term effectively views their data as coming from an experiment." This may be an extreme view and many researchers working with, for example, registry data would not spontaneously consider their commonly used methods experimental. Experiments can be divided into several categories, such as laboratory, field and survey.

Survey experiments has been the main method used in the essays comprising this thesis and most of the data used has been collected online. The enormous increase in internet usage over the last two decades has greatly increased the opportunities for conducting empirical research and collecting data online. Compared to a standard laboratory experiment, the researcher loses some control over the experiment. What is gained is the possibility of reaching diverse samples of the population. I would also argue that online survey experiments more accurately reflect everyday behavior, especially when people rely on computers, smartphones and tablets. Just to take an example, where do most people perform their financial tasks? Where they file their taxes? Many Swedes have chosen to get all their mail online. When people can participate in research from the comfort of their own home, we obtain more authentic answers that reflect everyday situations.

The results in Essay I are based on a large-scale survey with a diverse sample of the Swedish population. All respondents answered the same questions, with the same formulation, and in the same order. In Essay II I use field data from the Swedish Standardized Scholastic Aptitude Test. I also collected data using Amazon Mechanical Turk (MTurk). This data consists of an experimental part and a survey part. In Essay III I conduct an online vignette experiment with students. In Essay VI I use a large-scale survey experiment with a diverse sample of the general population.

To collect the data used in Essay I and Essay IV web links were distributed to participants; the link took them to an online survey that they completed at their convenience. The links were sent out to the Swedish population by Origo Group (previously CMA). They have access to several online panels and their algorithms make sure that the links reached a representative sub-sample of the population in terms of demographic variables such as age, gender and geographical spread. In Essay III I also use a web-based approach, but instead I sent a survey link to students at my university. The main task in this experiment was a series of short descriptive thought scenarios. In Essay II I use Amazon Mechanical Turk (MTurk). Here participants were randomly assigned to one of four experimental conditions. I also use "natural" 
or field data from the Swedish Standardized Scholastic Aptitude Test (sweSAT). This is a test that people in Sweden can take twice a year and I use a naturally occurring variation in this test. For this reason I could not control the information the participants received, but I could observe the outcome. This is the largest drawback of field data. The advantage is that the participants chose to participate without any influence from the researcher and are unaware that they are participating in an experiment.

In contrast, the advantage of using experimental methods is the possibility to vary only the aspect of interest and in a controlled manner. The main drawback is the difficulty with generalizability when using small or non-representative test populations. The obvious advantage of using large-scale survey experiments is that the researcher can reach a diverse sample of the population and remedy part of the concern with generalizability. Using student samples can be acceptable if we do not expect the student group to differ from the population we wish to generalize to in a systematic way a priori (Harrison \& List, 2004). This was the case for the data collection in Essay III. Student populations have also been shown to not be that different from other samples (Exadaktylos et al., 2013). Using a student population can, however, be an issue if one suspects that they differ from a general sample in key determinants. People's political view (or worldview) was an important feature in Essay IV, since we suspected that students differ in their political views from a broader sample of the population, we chose to collect the data from a more diverse sample.

But how about generalizability? There are studies considering this issue specifically. In the case of survey experiments Mullinix et al. (2015) show recent results that strengthen the confidence of the generalizability of student samples, online samples and opt-in samples. They find that many of the treatment effects replicate and are comparable to that of the general population. Results from survey experiments have also been shown to replicate real life behavior (Hainmueller et al., 2015). Likewise, issues have been raised with using samples from MTurk (Krupnikov \& Levine, 2014); however, other studies have found that people MTurk data is for comparable quality to other samples (Kees et al., 2017).

Even though this is reassuring, the question of biased samples will always be an issue in any type of study that rely on a sub-set of a population and wishes to generalize the results. To address this, there is a growing movement within the social sciences that is concerned with replicability (Camerer et al., 2018). I see this as a positive development for the social sciences. In the end, the only way to ensure reliable treatment effects, from essentially any type of study, is through repeated replication. By replication I mean both "pure" replications, utilizing the 
same measurements as the original study, and "conceptual" replications. This research must be nurtured to ensure reliability and validity of results from social sciences studies.

This development does, however, raise further issues in terms of familiarity with different types of experimental tasks. This topic is still only casually discussed within the literature. When our reach extends to more people and we are able to acquire even larger samples, we also run the risk of familiarizing people with our most commonly used instruments. Because of this it is only prudent that we start to ask what effect this familiarity will have in the future. All of these developments constitute interesting challenges for the social sciences, and I look forward to seeing where these developments take us and being a part of taking on these challenges.

\section{Some reflections on the findings}

The findings in this thesis confirm a large heterogeneity in people's ability to handle the complexities of everyday (financial) decisions. The results have shown that financial literacy is essential to us when we act as our own business manager. More familiarity with financial concepts is associated with more frequent engagement in sound financial practices; it also makes people less anxious about financial matters. With regards to preferences for payment structures the considered traits and abilities did not explain the choices people made. Yet, people showed preferences for lump sums, in both the loss and gain domain. For policy makers concerned with household debt, this result is reassuring. If people have the possibility, they will want to reduce their debt straight away. This tendency is stronger for women than men.

The thesis also finds that biased reasoning processes are widespread in everyday evaluation of information. In the role as our own business manager biased reasoning may have adverse implication if it inhibits us to partake in certain behaviors or practices. Yet in other situations the effect can be quite the opposite. It makes the everyday information stream less demanding to interpret and everyday decisions can be taken more swiftly. From a societal standpoint it's another matter. The fact that I find clear evidence of motivated reasoning may be expected. Yet these biased reasoning processes are troublesome. A fundamental aspect of a deliberative democracy is that people are able to generate reliable and correct assessments from the information at hand when making judgments and decisions. Motivated reasoning inhibits these objective assessments. We also have to consider that we live in a new informational reality, where consumption of information is increasingly tailored to our preferences and social belonging. At an increasing rate, people are primarily confronted with information that supports 
their already existing beliefs and values. In combination with widespread motivated reasoning this constitute a clear societal challenge, or the result will be further societal fractionalization. The results of this thesis indicate that better numeric ability lessens the tendencies of motivated reasoning, however this goes against what previous literature on the subject has found (Kahan et al., 2017). We therefore have to keep investigating the underpinnings of motivated reasoning in order to tackle the consequences of this phenomena in the future.

Considering the positive effects of both numeracy and financial literacy that has been shown to have in this thesis, it is troubling when a gender gap is observed in these abilities. With regards to financial literacy this thesis finds that one reason for the observed gender gap could be a stereotype threat toward the financial domain, a threat especially salient for women. However, the results also indicated that providing financial information helped both men and women in their understanding of financial concepts. Even though the gender gap persisted, it is good news for policy makers who wish to boost peoples financial understanding and encourage people in their role as their own business manager. Giving people more information helped them rather than threatened them. Furthermore, this thesis finds that confidence in financial matters is as important as competence. These are important findings for policy makers concerned with increasing the financial wellbeing of people. Considering the indication of a stereotype threat toward the financial domain, boosting financial confidence may be especially important for women. This said, it is important that confidence is boosted in combination with efforts to increase competence. If these efforts do not go together any educational efforts are likely to backfire and lead to inflated confidence without a sound foundation of financial understanding. This also constitute an important future challenge in order to ensure that men and women are equally likely to prosper in the role as their own business manager.

\section{Summary of the thesis}

\section{Essay I: Competence, confidence, and gender: The role of perceived and actual financial literacy in household finance}

With increased individual responsibility for one's financial future, the individual decision maker must make sure to be capable of handling everyday finance. This study investigates if individual differences in perceived and actual financial literacy, numeracy, and cognitive reflection influence how the frequency of our engagement in everyday financial behaviors and if these abilities have a direct influence on subjective financial wellbeing. Previous literature 
has focused on the effect on financial behaviors, so we address the additional link to financial wellbeing. This is an important question since financial wellbeing is the main objective with, for example, financial education. The American Consumer Financial Protection Bureau (CFPB, 2015) went so far as to state that "...the ultimate measure of success for financial literacy efforts should be individual financial wellbeing" (CFPB, p. 9). Meta-analyses studies have shown only weak effects of educational attempts in financial literacy. A reason could be a discrepancy between what affects financial behaviors and what affects financial wellbeing. Our definition of financial wellbeing is unique, because we focus on self-perceived wellbeing rather than objectively set standards. We use a large-scale sample $(n=2,063)$ of the adult Swedish population. Our main results indicate that both actual and perceived financial literacy predicts financial behaviors, but numeracy and cognitive reflection cannot be linked to financial behavior. Both types of financial literacy can serve as a buffer against financial anxiety, while numeracy and cognitive reflection do not. Women are more anxious about financial matters even though they tend to engage more frequently in the considered financial behaviors. Our findings help to understand heterogeneity among individuals' propensity to engage in sound financial behaviors.

\section{Essay II: Threatening finance? Examining the gender gap in financial literacy}

A persistent gender gap, in which men outperform women, is usually observed in financial literacy across the world. This gender gap is puzzling, particularly in industrialized societies, were more women than men attend college and university and are well integrated in the accounting, baking and finance sector. It has empirically been shown that financial literacy is associated with higher likelihood of financial wealth and of participating in the stock market, better provision for retirement, and less anxiety about financial matters. It is therefore evident that financial literacy is important for enabling the individual to navigate modern financial life. Systematic differences between men and women in financial literacy therefore imply that women are less likely than men to prevail in the financial markets.

Understanding why women display lower levels of financial literacy than men is crucial for developing policies to reduce gender inequalities and improve women's financial behavior. In a series of studies, I investigate whether the observed gender gap in financial literacy can be identified in nonnumerical contexts, if it can be related to confidence in financial matters, and if it can be attributed to stereotype threat, which posits that inbuilt prejudices about gender and 
finance undermine women's performance of financial tasks. I used data from the Swedish Standardized Scholastic Aptitude test $(n=40,662)$ to investigate if reading comprehension between men and women differs for topics related to finance compared to other topics. Furthermore, I conducted a large-scale online data collection $(n=1,989)$ involving a survey on financial verbal comprehension and an experiment that manipulated the salience of the financial content across conditions when assessing financial literacy. The results show that the observed gender gap in financial literacy is robust even in nonnumerical financial contexts and suggest that a stereotype threat for women in the financial domain might be present. The gender gap in financial literacy could not be attributed to a difference in (displayed) confidence.

\section{Essay III: Preferences for lump-sum over divided payment structures}

In a vignette experiment $(n=238)$, I investigate if people display systematic preferences for lump-sum or divided payment structures and how these preferences differ in gain (benefit) and loss (payment) situations. I investigate payments that belong to one underlying event, such as when people can choose to pay immediately or in installments. I attempt to examine and contrast several theoretical predictions for this type of behavior. I also explore if individual differences in time preferences, risk preferences, numeracy and financial literacy are associated with preferences of payment structure. The aggregate results show a preference for paying and receiving money as lump sums. For the gain scenarios, this is not surprising if the lump-sum option is offered today; however, it is a bit more surprising if it is offered in the future. For the losses (or debts) the results indicate that people do not wish to have outstanding debt, this is especially true for women who systematically choses to reduce the debt as soon as possible. We find no systematic indication that individual differences in time preferences, risk preferences, numeracy and financial literacy play a role in this type of decision. These results have consequences for how we think about cumulative neglect and consumption patterns.

\section{Essay IV: Motivated reasoning when assessing the effect of refugee intake}

In this study we explore if differences in worldview ideology hinder people from objectively interpreting the effect of incoming refugees. It is important to investigate motivated reasoning outside the traditional American setting. For this setting this biased line of reasoning has been shown for a wide range of domains. We try to bring motivated reasoning into a Swedish context with the topic of immigrants and refugees. In an experiment with Swedish adults $(n=1,015)$, we investigate if people were able to interpret numerical information on the effects of refugee 
intake on the crime rate. Since the Swedish political landscape is quite different from that of the United States we investigate several potential polarizing lines but focus on worldview ideology, whether people identify as nationally or globally oriented.

Our results show clear evidence of motivated reasoning along the lines of worldview ideology. In scenarios where the presence of refugees was associated with a higher crime rate, nationally oriented people were 18 percentage points more likely to make the correct assessment than globally oriented people. Likewise, in scenarios where refugee intake was associated with lower crime rate, nationally oriented people were percentage points less likely to make the correct assessment, than globally oriented people. Individuals with higher numeric ability were less likely to engage in motivated reasoning, suggesting that motivated reasoning is driven by feelings and emotional cues rather than by deliberate analytical processes. 


\section{References}

Alessie, R. O. B., Van Rooij, M., \& Lusardi, A. (2011). Financial literacy and retirement preparation in the Netherlands. Journal of Pension Economics and Finance, 10(4), 527-545.

Almenberg, J., \& Dreber, A. (2015). Gender, stock market participation and financial literacy. Economics Letters, 137, 140-142.

Almenberg, J., \& Widmark, O. (2011). Numeracy, Financial Literacy and Participation in Asset Markets, Available at: https://ssrn.com/abstract=1756674.

Banks, J., \& Oldfield, Z. (2007). Understanding Pensions: Cognitive Function, Numerical Ability and Retirement Saving. Fiscal Studies, 28(2), 143-170.

Bastardi, A., Uhlmann, E. L., \& Ross, L. (2011). Wishful Thinking: Belief, Desire, and the Motivated Evaluation of Scientific Evidence. Psychological Science(6), 731-732.

Becker, G. S. (1962). Investment in Human Capital: A Theoretical Analysis. Journal of Political Economy, 70(5, Part 2), 9-49.

Bénabou, R. (2015). Conférence Jean-Jacques Laffont the economics of motivated beliefs. Revue d'Economie Politique, 125(5), 665-685.

Bolsen, T., Druckman, J. N., \& Cook, F. L. (2014). The Influence of Partisan Motivated Reasoning on Public Opinion. Political Behavior, 36(2), 235-262.

Camerer, C. F., Dreber, A., Holzmeister, F., Ho, T.-H., Huber, J., Johannesson, M., . . Wu, H. (2018). Evaluating the replicability of social science experiments in Nature and Science between 2010 and 2015. Nature Human Behaviour, 2(9), 637-644.

CFPB. (2015). Financial well-being: The goal of financial education. Retrieved from Consumer Financial Protection Bureau. Washington DC. Available at: https://www.consumerfinance.gov/data-research/research-reports/

Driva, A., Lührmann, M., \& Winter, J. (2016). Gender differences and stereotypes in financial literacy: Off to an early start. Economics Letters, 146(September), 143-146.

Drummond, C., \& Fischhoff, B. (2017). Individuals with greater science literacy and education have more polarized beliefs on controversial science topics. Proceedings of the National Academy of Sciences of the United States of America, 114(36), 95879592.

Dunlap, R. E., McCright, A. M., \& Yarosh, J. H. (2016). The Political Divide on Climate Change: Partisan Polarization Widens in the U.S. Environment: Science and Policy for Sustainable Development, 58(5), 4-23. 
Exadaktylos, F., Espín, A. M., \& Brañas-Garza, P. (2013). Experimental subjects are not different. Scientific Reports, 3(1213).

Falk, A., \& Heckman, J. J. (2009). Lab Experiments Are a Major Source of Knowledge in the Social Sciences. Science, 326(5952), 535-538.

Feingold, A. (1988). Cognitive gender differences are disappearing. American Psychologist, 43(2), 95-103.

Fonseca, R., Mullen, K. J., Zamarro, G., \& Zissimopoulos, J. (2012). What Explains the Gender Gap in Financial Literacy? The Role of Household Decision Making. Journal of Consumer Affairs, 46(1), 90-106.

Fünfgeld, B., \& Wang, M. (2009). Attitudes and behaviour in everyday finance: evidence from Switzerland. International Journal of Bank Marketing, 27(2), 108-128.

Ghazal, S., Cokely, E., T. , \& Garcia-Retamero, R. (2014). Predicting biases in very highly educated samples: Numeracy and metacognition. Judgment and Decision Making, 9(1), 15-34.

Hainmueller, J., Hangartner, D., \& Yamamoto, T. (2015). Validating vignette and conjoint survey experiments against real-world behavior. Proceedings of the National Academy of Sciences, 112(8), 2395-2400.

Harrison, G. W., \& List, J. A. (2004). Field Experiments. Journal of Economic Literature, 42(4), 1009-1055.

Hedges, L., V. , \& Nowell, A. (1995). Sex Differences in Mental Test Scores, Variability, and Numbers of High-Scoring Individuals. Science, 269(5220), 41-45.

Hung, A., A. , Parker, A., M. , \& Yoong, J., K. (2009). Defining and Measuring Financial Literacy, RAND Working Paper Series WR-708.

Huston, S. J. (2010). Measuring Financial Literacy. Journal of Consumer Affairs, 44(2), 296316.

Hyde, J. S., Fennema, E., \& Lamon, S. J. (1990). Gender differences in mathematics performance: A meta-analysis. Psychological Bulletin, 107(2), 139-155.

Kahan, D. M., Peters, E., Dawson, E. C., \& Slovic, P. (2017). Motivated numeracy and enlightened self-government. Behavioural Public Policy, 1(1), 54-86.

Kahan, D. M., Peters, E., Wittlin, M., Ouellette, L. L., Slovic, P., Braman, D., \& Mandel, G. (2012). The polarizing impact of science literacy and numeracy on perceived climate change risks. Nature Climate Change, 2(10), 732-735. 
Kaya, O. (2014). Is perceived financial inadequacy persistent? Review of Income and Wealth, 60(4), 636-654.

Kees, J., Berry, C., Burton, S., \& Sheehan, K. (2017). An Analysis of Data Quality:

Professional Panels, Student Subject Pools, and Amazon's Mechanical Turk. Journal of Advertising, 46(1), 141-155.

Krupnikov, Y., \& Levine, A. S. (2014). Cross-Sample Comparisons and External Validity. Journal of Experimental Political Science, 1(1), 59-80.

Kunda, Z. (1990). The case for motivated reasoning. Psychological Bulletin, 108(3), 480.

Lord, C. G., Ross, L., \& Lepper, M. R. (1979). Biased assimilation and attitude polarization: The effects of prior theories on subsequently considered evidence. Journal of Personality and Social Psychology, 37(11), 2098-2109.

Lusardi, A. (2008). Household saving behavior: The role of literacy, information and financial education programs, NBER Working Paper Series No. 13824, Available at: https://www.nber.org/papers/w13824.

Lusardi, A., \& Mitchell, O. S. (2008). Planning and Financial Literacy: How Do Women Fare? American Economic Review, 98(2), 413-417.

Lusardi, A., \& Mitchell, O. S. (2014). The Economic Importance of Financial Literacy: Theory and Evidence. Journal of Economic Literature, 52(1), 5-44.

Mullinix, K. J., Leeper, T. J., Druckman, J. N., \& Freese, J. (2015). The Generalizability of Survey Experiments. Journal of Experimental Political Science, 2(2), 109-138.

Nickerson, A. M., \& Louis, W. R. (2008). Nationality Versus Humanity? Personality, Identity, and Norms in Relation to Attitudes Toward Asylum Seekers1. Journal of Applied Social Psychology, 38(3), 796-817.

O'Donoghue, T., \& Rabin, M. (2001). Choice and Procrastination. The Quarterly Journal of Economics, 116(1), 121-160.

Reyna, V. F., Nelson, W. L., Han, P. K., \& Dieckmann, N. F. (2009). How numeracy influences risk comprehension and medical decision making. Psychological Bulletin, 135(6), 943-973.

Rosselli, M., Ardila, A., Matute, E., \& Inozemtseva, O. (2009). Gender Differences and Cognitive Correlates of Mathematical Skills in School-Aged Children. Child Neuropsychology, 15(3), 216-231.

Skagerlund, K., Lind, T., Strömbäck, C., Tinghög, G., \& Västfjäll, D. (2018). Financial literacy and the role of numeracy-How individuals attitude and affinity with numbers 
influence financial literacy. Journal of Behavioral and Experimental Economics, 74(June), 18-25.

Steele, C. M., Spencer, S. J., \& Aronson, J. (2002). Contending with group image: The psychology of stereotype and social identity threat. Advances in Experimental Social Psychology, 34, 379-440.

Strömbäck, C., Lind, T., Skagerlund, K., Västfjäll, D., \& Tinghög, G. (2017). Does selfcontrol predict financial behavior and financial well-being? Journal of Behavioral and Experimental Finance, 14(June), 30-38.

Van Bavel, J. J., \& Pereira, A. (2018). Opinion: The Partisan Brain: An Identity-Based Model of Political Belief. Trends in Cognitive Sciences, 22, 213-224.

Washburn, A. N., \& Skitka, L. J. (2017). Science Denial Across the Political Divide: Liberals and Conservatives Are Similarly Motivated to Deny Attitude-Inconsistent Science. Social Psychological and Personality Science, 9(8), 972-980.

von Hippel, C., Sekaquaptewa, D., \& McFarlane, M. (2015). Stereotype threat among women in finance: negative effects on identity, workplace well-being, and recruiting. Psychology of Women Quarterly, 39(3), 405-414. 


\section{Essays}

The essays associated with this thesis have been removed for copyright reasons. For more details about these see:

http://urn.kb.se/resolve?urn=urn:nbn:se:liu:diva-156648 


\section{FACULTY OF ARTS AND SCIENCES}

Linköping Studies in Arts and Sciences No. 770, 2019

Department of Management and Engineering

Linköping University

SE-581 83 Linköping, Sweden

www.liu.se 